\title{
A prospective analysis of GERD after POEM on anterior myotomy
}

\author{
Hironari Shiwaku ${ }^{1}$ Haruhiro Inoue ${ }^{2} \cdot$ Takamitsu Sasaki $^{1} \cdot$ Kanefumi Yamashita $^{1} \cdot$ \\ Toshihiro Ohmiya $^{1} \cdot$ Shinsuke Takeno $^{1} \cdot$ Satoshi Nimura $^{3} \cdot$ Yuichi Yamashita $^{1}$
}

Received: 12 March 2015 / Accepted: 1 August 2015/Published online: 28 September 2015

(C) Springer Science+Business Media New York 2015

\begin{abstract}
Background Peroral endoscopic myotomy (POEM) is an emerging, minimally invasive procedure capable of overcoming limitations of achalasia treatments, but gastroesophageal reflux disease (GERD) after POEM is of concern and its risk factors have not been evaluated. This prospective study examined GERD and the association of POEM with reflux esophagitis.

Methods Achalasia patients were recruited from a single center. The pre- and postoperative assessments included Eckardt scores, manometry, endoscopy, and $\mathrm{pH}$ monitoring.

Results Between September 2011 and November 2014, 105 patients underwent POEM; 70 patients were followed up 3 months after POEM. Postoperatively, significant reductions were observed in lower esophageal sphincter (LES) pressure [from $40.0 \pm 22.8$ to $20.7 \pm 14.0 \mathrm{mmHg}$ $(P<0.05)$ ], LES residual pressure [from $22.1 \pm 13.3$ to $11.4 \pm 6.6 \mathrm{mmHg}(P<0.05)$ ], and Eckardt scores [from $5.7 \pm 2.5$ to $0.7 \pm 0.8(P<0.05)]$. Symptomatic GERD and moderate reflux esophagitis developed in 5 and 11 patients (grade $\mathrm{B}, n=8$; grade $\mathrm{C}, n=3$ ), respectively, and were well controlled with proton pump inhibitors. Univariate logistic regression analysis revealed integrated relaxation pressure was a predictor of $\geq$ grade $\mathrm{B}$ reflux
\end{abstract}

Hironari Shiwaku

hiro.shiwaku@gmail.com

1 Department of Gastroenterological Surgery, Faculty of Medicine, Fukuoka University, Fukuoka, Japan

2 Digestive Disease Center, Showa University Koto Toyosu Hospital, Tokyo, Japan

3 Department of Pathology, Faculty of Medicine, Fukuoka University, Fukuoka, Japan esophagitis. No POEM factors were found to be associated with reflux esophagitis.

Conclusion POEM is effective and safe in treating achalasia, with no occurrence of clinically significant refractory GERD. Myotomy during POEM, especially of the gastric side, was not associated with $\geq$ grade B (requiring medical intervention) reflux esophagitis. Extended gastric myotomy $(2-3 \mathrm{~cm})$ during POEM is recommended to improve outcomes.

\section{Keywords Achalasia $\cdot$ GERD $\cdot$ POEM}

Achalasia, a rare functional motility disorder of the esophagus, is characterized by incomplete lower esophageal sphincter (LES) relaxation, increased LES tone, and aperistalsis of the esophagus [1].

Clinical symptoms of achalasia include dysphagia, regurgitation, and chest pain. Decreasing the pressure at the LES is the only valid therapeutic approach to eliminate or reduce these symptoms, and endoscopic procedures (balloon dilations and botulinum toxin injection therapy) and surgery were the available treatments until peroral endoscopic myotomy (POEM) [2-15].

Balloon dilations and botulinum toxin injections are less invasive than surgery, but do not reliably produce consistent effects. However, surgery is superior to other therapeutic methods in that it has a curative effect with consistent outcomes, and the Heller myotomy with Dor fundoplication is the most popular technique $[7,16,17]$.

Initially, fundoplication was not performed when Heller reported this procedure in early 1900 [18]. Achalasia patients were freed from the symptoms on treatment with Heller myotomy, but the high incidence of gastroesophageal reflux (GER) became evident over time [7]. 
Therefore, Heller myotomy with fundoplication became popular. POEM is a revolutionary therapy for achalasia that was reported in 2008 by Inoue et al. [19]. POEM uses peroral endoscopy to incise the LES and its inner circular muscle; therefore, it is referred to as a "Heller myotomy that does not cut the body surface." Because POEM is an esophageal myotomy, similar to the Heller myotomy, gastroesophageal reflux disease (GERD) after POEM is a major outcome that should be examined in the clinical setting.

There exist several papers reporting that GERD after POEM is not a problem clinically [19-23]. However, risk factors for GERD after POEM have not been reported or studied. This study aimed to examine GERD after POEM and to investigate whether POEM (especially myotomy of the gastric side) is associated with reflux esophagitis (> grade B, LA classification) that requires medical treatment clinically.

\section{Methods}

\section{Patients}

The data for our single-center POEM procedures were collected prospectively. The use of the POEM procedure was approved by the Institutional Review Board (IRB) of Fukuoka University Hospital, and written informed consent was obtained from all patients prior to enrollment in the study. The inclusion criterion was a confirmed diagnosis of achalasia.

Patients with previous history of fundoplication and those on proton pump inhibitors (PPI) due to anticoagulant therapy were excluded, as were patients who had undergone posterior myotomy.

\section{Investigations before and after POEM}

Pre- and postoperative symptoms were quantified with Eckardt scores [24]. Patients were weighed, and tests (manometry, endoscopy, barium swallow, and computed tomography $[\mathrm{CT}]$ ) were performed preoperatively. Three months after POEM, manometry and endoscopy were performed to evaluate the effectiveness of POEM and determine the presence and extent of postsurgical reflux esophagitis. In addition, gastroesophageal reflux was also evaluated 3 months postoperatively by 24-h pH monitoring using the ZepHr ${ }^{\circledR}$ Impedance/pH Reflux Monitoring System (Sandhill Scientific, USA).

\section{Preparation before POEM}

Patients were hospitalized 1 day before the POEM procedure so that esophagogastroduodenoscopy (EGD) could be performed to ensure all food remnants were removed from the esophagus prior to surgery.

\section{Equipment used for POEM}

A forward-viewing endoscope with an outer diameter of $9.8 \mathrm{~mm}$ (GIF-H260, Olympus Medical Systems, Japan), which is routinely employed for upper gastrointestinal (GI) examinations, was used with a short ST hood (DH-28GR, Fujifilm, Japan). A triangle-tip knife(KD-640L, Olympus) was used to create the submucosal tunnel as well as to divide circular muscle bundles. Coagulating forceps (FD-411QR Coagrasper, Olympus) were used to close larger vessels prior to dissection and for hemostasis. Carbon dioxide gas was used for insufflation during the procedure with a $\mathrm{CO}_{2}$ insufflator (UCR, Olympus). For electrosurgery, the VIO 300D electrogenerator (ERBE, Tübingen, Germany) was used. Finally, hemostatic clips (HX-610-90L EZ Clip and HX-610-90S EZ Clip Olympus) were applied for closure of the mucosal entry site.

\section{The POEM procedure}

The first case was performed by Haruhiro Inoue, who pioneered the POEM technique for clinical practice, and the next ten cases were operated upon under his supervision and as described by Inoue et al. [19]. After injection of approximately $10 \mathrm{~mL}$ of glycerol mixed with $0.3 \%$ indigo carmine into the submucosal layer, a longitudinal mucosal incision was made in the mucosal surface to access the submucosal space. A submucosal tunnel was created in the one to two o'clock position on the ventral aspect of the esophagus to preserve the angle of His, and was then extended past the esophagogastric junction (EGJ) for $2-3 \mathrm{~cm}$ onto the gastric cardia. A proximal-to-distal circular myotomy was performed with care to preserve the longitudinal muscle layers of the esophagus and stomach. Preservation of the longitudinal muscle sheet potentially avoids unnecessary injury to the structures adjacent to the esophagus.

The secure incision of the LES was identified by the following points:

- length from incisor teeth to EGJ as a reference position for the scope

- narrowing of the esophageal lumen closer to the LES and then opening wide in the stomach when creating a submucosal tunnel

- change from palisade vessels (anatomically equivalent to the LES) to increased irregularity and augmentation of the vessels underlying the mucosa as viewed from the submucosal tunnel

- smooth endoscope passage through the LES inside the true esophageal lumen and mucosa of stomach is seen from the esophageal lumen after the myotomy 
- the branch of the left gastric artery and oblique muscle in the submucosal tunnel of the gastric side (sometimes, this cannot be confirmed)

After spraying an antibiotic (80 mg gentamycin) into the tunnel, the mucosal entry was closed using endoscopic clips.

\section{Postprocedural management}

Intravenous antibiotics were administered for 3 days after the procedure. On the first day after surgery, an endoscopy was performed to confirm mucosal integrity, as was barium swallow to confirm the smooth passage of contrast media into the stomach without leakage or stasis. A liquid diet was started on the day after surgery, followed by soft diet on day 2 post-POEM, with resumption of a normal diet on day 3 post-POEM. On discharge, patients were prescribed a PPI for 1 month and, thereafter, asked to discontinue the PPI until the postoperative examination.

\section{Estimation of GERD}

GERD was evaluated on the basis of symptoms and endoscopic findings, together with 24-h $\mathrm{pH}$ monitoring 3 months after POEM [25-28].

Because reflux esophagitis (>grade B, LA classification) requires medical treatment, it was analyzed statistically. A PPI was prescribed for patients diagnosed with symptomatic GERD or reflux esophagitis (>grade B, LA classification); these patients were re-evaluated another 3 months later by elicitation of symptoms during examination and an upper GI endoscopy.

\section{Statistical analysis}

Pre- versus postoperative assessment of Eckardt score, LES pressure, and LES residual pressure was analyzed using Student's $t$ test for paired samples. $P$ value $<0.05$ was considered statistically significant. Continuous data are reported as the mean \pm standard deviation (SD) if they are normally distributed, and as the medians and interquartile ranges (IQRs) if their distribution was not normal. Categorical data are presented as numbers (n) and percentages (\%). A logistic regression analysis was used to assess independent contributions of the variables to reflux esophagitis, and the results are presented as odds ratios (ORs) and $95 \%$ CIs. A $P$ value $<0.05$ was considered to be statistically significant.

All statistical analyses were performed using the SPSS v 21.0 software program for Windows (SPSS, Chicago, Illinois, USA).

\section{Results}

\section{Patient background}

POEM was carried out in 105 patients between September 2011 and November 2014. A questionnaire assessment, endoscopy of the upper GI tract, and 24-h pH monitoring were done for 70 cases at 3 months or later after the POEM (Table 1). Based on the endoscopic findings, reflux esophagitis (LA classification) grades A, B, and C occurred in 31,8 , and 3 patients, respectively. No grade D severe reflux esophagitis was reported (Fig. 1). Patient demographics, stratified by the presence or absence of reflux esophagitis (grade B, LA classification), are described in Table 2.

Of the 70 patients, including 29 men and 41 women, with achalasia, the average age was $48.8 \pm 18.8$ (range 17-86) years. Fourteen patients had undergone balloon dilation prior to inclusion in this study. No severe complications were reported.

No $>$ grade III adverse events (as per the ClavienDindo classification) were reported during this study [29]. Mucosal injury occurred in four cases, all of which were treated by conservative therapy.

The average total length of the myotomy was $12.6 \pm 4.3$ (range 5-26) $\mathrm{cm}$, and the average length of the gastric myotomy was $2.6 \pm 1.0$ (range $1-5$ ) $\mathrm{cm}$. To evaluate the interoperative esophageal pressure, only properly measured values were utilized for the statistical analysis. It should be noted that there were several patients with improperly inserted catheter, exam discontinued before completion, or who did not undergo the examination.

The mean preoperative and postoperative LES pressures were $40.0 \pm 22.8$ and $20.7 \pm 14.0 \mathrm{mmHg}$, respectively, indicating a statistically significant decrease after POEM. The mean preoperative and postoperative LES residual pressures were $22.1 \pm 13.3$ and $11.4 \pm 6.6 \mathrm{mmHg}$. Furthermore, the Eckardt score significantly decreased from $5.7 \pm 2.5$ preoperatively to $0.7 \pm 0.8$ postoperatively (Fig. 2).

\section{Incidence of reflux esophagitis after POEM}

Postoperative endoscopic findings led to the classification of $44 \%(31 / 70), 12 \%(8 / 70)$, and $4 \%(3 / 70)$ of patients as having grades $\mathrm{A}, \mathrm{B}$, and $\mathrm{C}$ reflux esophagitis, respectively, as per the LA classification (Fig. 1). Data for these patients are incomplete because three patients refused to undergo 24-h pH monitoring; however, analysis of data from patients who underwent 24-h $\mathrm{pH}$ monitoring revealed a positive correlation (correlation coefficient $=0.489$; Fig. 3) between $\mathrm{pH}$ and endoscopy parameters. Five 
Table 1 Patient demographics and perioperative characteristics

\begin{tabular}{ll}
\hline Age [years, mean \pm SD (range)] & $48.8 \pm 18.8$ (17-86) \\
Sex & 41 \\
Men & 29 \\
Women & \\
Type of achalasia & 64 \\
Straight type & 6 \\
Sigmoid type & \\
Chicago classification & 6 \\
Type I & 55 \\
Type II & 9 \\
Type III & 14 \\
Primary procedure, $n$ & 14 \\
Balloon dilatation & $148.6 \pm 45.9(75-345)$ \\
Length of procedure (range), minutes & \\
Myotomy length, mean (range), cm & $12.6 \pm 4.3(5-26)$ \\
Total & $10.0 \pm 4.0(3-23)$ \\
Esophageal & $2.6 \pm 1.0(1-5)$ \\
Gastric & $7.3 \pm 2.5(3-21)$ \\
Postoperative stay, mean \pm SD (range), days & \\
\hline
\end{tabular}

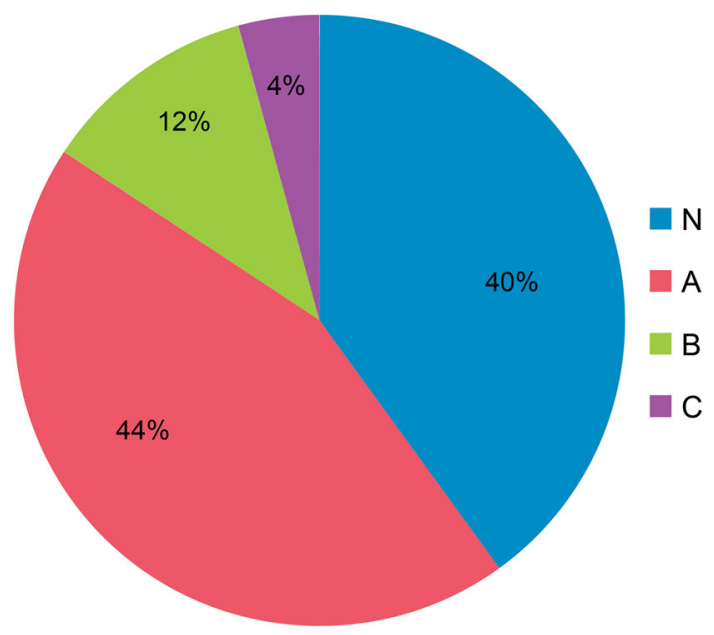

Fig. 1 Results of postoperative reflux esophagitis. Endoscopic finding at 3 months after POEM showed that $84 \%$ of the patients are classified as grade $\mathrm{N}$ or $\mathrm{A}$, with $12 \%$ in grade $\mathrm{B}$, and $4 \%$ in grade $\mathrm{C}$

patients were diagnosed with symptomatic GERD (4 with a grade $\mathrm{A}$ and 1 with a grade $\mathrm{B}$ LA classification). Treatment with PPI in patients with reflux esophagitis and symptomatic GERD resulted in an improvement.

\section{Analysis of the factors predicting the development of reflux esophagitis}

A univariate logistic regression analysis was performed on the factors shown in Table 3 to identify the factors that could predict the development of reflux esophagitis of greater than grade B severity (LA classification). We found that IRP was significantly affected the development of reflux esophagitis of grade B or higher severity.

POEM-related variables, such as the length of the myotomy, did not show a significant correlation with postoperative reflux esophagitis of grade B or higher severity.

\section{Discussion}

In recent years, POEM has been increasingly performed for the treatment of achalasia and related disorders [30-33]. POEM is less invasive and has a higher curative rate compared with conventional therapeutic methods; therefore, POEM is expected to become the standard treatment, worldwide, for esophageal motor dysfunction, including achalasia, in the near future. However, there are limited studies comparing POEM with conventional therapeutic methods, and one of the factors that needs evaluation is GERD after POEM.

During Heller myotomy (laparotomy), the adjacent structures surrounding the distal esophagus (e.g., the phrenoesophageal ligament) are inevitably dissected circumferentially, and the esophagus is pulled to the side of the abdominal cavity to perform a myotomy on the esophagus. This procedure is linked to an impairment of the natural antireflux mechanisms and causes postoperative refractory reflux esophagitis. Therefore, the Heller myotomy requires fundoplication to prevent reflux. 
Table 2 Patient demographics stratified by the presence or absence of reflux esophagitis $\geq$ grade $\mathrm{B}$

\begin{tabular}{|c|c|c|c|c|}
\hline & $N$ & GERD grade N/A & $n$ & GERD grade $\mathrm{B} / \mathrm{C}$ \\
\hline \multicolumn{5}{|l|}{ Before POEM } \\
\hline $\operatorname{Sex}(M / F)$ & 59 & $(25 / 34)$ & 11 & $(4 / 7)$ \\
\hline Age (years) & 59 & $\begin{array}{l}48.2 \pm 19.1 \\
43.0(33.0,62.0)\end{array}$ & 11 & $\begin{array}{l}51.7 \pm 17.8 \\
51.0(40.0,66.0)\end{array}$ \\
\hline BMI (before POEM; $\mathrm{kg} / \mathrm{m}^{2}$ ) & 59 & $\begin{array}{l}20.6 \pm 3.27 \\
19.9(18.4,22.9)\end{array}$ & 11 & $\begin{array}{l}21.1 \pm 3.6 \\
20.8(18.5,22.5)\end{array}$ \\
\hline \multicolumn{5}{|l|}{ Degree of dilatation } \\
\hline I & 33 & & 6 & \\
\hline II & 24 & & 5 & \\
\hline III & 2 & & 0 & \\
\hline \multicolumn{5}{|l|}{ Type } \\
\hline Straight & 53 & & 11 & \\
\hline Sigmoid & 6 & & 0 & \\
\hline \multicolumn{5}{|l|}{ Chicago classification } \\
\hline Type I & 4 & & 2 & \\
\hline Type II & 48 & & 7 & \\
\hline Type III & 7 & & 2 & \\
\hline \multicolumn{5}{|l|}{ Primary procedure } \\
\hline None & 48 & & 8 & \\
\hline Balloon dilatation & 11 & & 3 & \\
\hline \multicolumn{5}{|l|}{ Hiatal hernia } \\
\hline None & 58 & & 10 & \\
\hline Present & 1 & & 1 & \\
\hline Eckardt score & 59 & $\begin{array}{l}5.7 \pm 2.4 \\
6.0(3.0,7.0)\end{array}$ & 11 & $\begin{array}{l}5.6 \pm 3.2 \\
5.0(3.0,9.0)\end{array}$ \\
\hline Mean LES pressure & 53 & $\begin{array}{l}40.7 \pm 23.7 \\
38.4(22.8,53.4)\end{array}$ & 8 & $\begin{array}{l}35.3 \pm 15.8 \\
43.0(20.7,46.8)\end{array}$ \\
\hline LES residual pressure & 47 & $\begin{array}{l}22.6 \pm 13.1 \\
21.2(12.7,29.7)\end{array}$ & 8 & $\begin{array}{l}19.0 \pm 14.9 \\
13.5(6.9,35.3)\end{array}$ \\
\hline IRP & 47 & $\begin{array}{l}35.1 \pm 14.7 \\
34.0(23.0,45.0)\end{array}$ & 8 & $\begin{array}{l}32.5 \pm 23.6 \\
21.00(18.3,52.3)\end{array}$ \\
\hline \multicolumn{5}{|l|}{ Perioperative details } \\
\hline Length of procedure & 59 & $\begin{array}{l}148.7 \pm 49.6 \\
140.0(120.0,165.0)\end{array}$ & 11 & $\begin{array}{l}148.2 \pm 17.4 \\
150.0(130.0,160.0)\end{array}$ \\
\hline Length of myotomy: total & 59 & $\begin{array}{l}12.3 \pm 4.3 \\
13.0(9.0,15.0)\end{array}$ & 11 & $\begin{array}{l}13.7 \pm 4.1 \\
13.0(10.0,17.0)\end{array}$ \\
\hline Length of myotomy: esophageal & 59 & $\begin{array}{l}9.8 \pm 4.0 \\
10.0(7.0,12.0)\end{array}$ & 11 & $\begin{array}{l}11.2 \pm 3.6 \\
12.0(8.0,14.0)\end{array}$ \\
\hline Length of myotomy: gastric & 59 & $\begin{array}{l}2.6 \pm 1.1 \\
3.0(2.00,3.0)\end{array}$ & 11 & $\begin{array}{l}2.5 \pm 1.0 \\
3.0(2.0,3.0)\end{array}$ \\
\hline Postoperative stay, days & 59 & $\begin{array}{l}7.2 \pm 2.5 \\
7.0(6.00,7.00)\end{array}$ & 11 & $\begin{array}{l}7.9 \pm 2.3 \\
7.0(6.0,9.0)\end{array}$ \\
\hline Mucosal injury (yes/no) & $4 / 55$ & & $0 / 11$ & \\
\hline 3 months after POEM & & & & \\
\hline BMI $\left(\mathrm{kg} / \mathrm{m}^{2}\right)$ & 59 & $\begin{array}{l}21.7 \pm 3.2 \\
21.4(19.7,23.5)\end{array}$ & 11 & $\begin{array}{l}21.9 \pm 3.6 \\
20.6(18.9,25.4)\end{array}$ \\
\hline Eckardt score & 59 & $\begin{array}{l}0.7 \pm 0.86 \\
0.00(0.00,1.00)\end{array}$ & 11 & $\begin{array}{l}0.7 \pm 0.8 \\
1.00(0.0,1.0)\end{array}$ \\
\hline
\end{tabular}


Table 2 continued

\begin{tabular}{lllll}
\hline & $N$ & GERD grade N/A & $n$ & GERD grade B/C \\
\hline Mean LES pressure & 49 & $20.8 \pm 14.3$ & 9 & $20.4 \pm 13.1$ \\
& & $19.5(13.7,24.9)$ & & $18.7(7.3,31.9)$ \\
LES residual pressure & \multirow{2}{*}{38} & $12.0 \pm 6.2$ & 9 & $8.6 \pm 8.1$ \\
& & $12.5(7.8,15.6)$ & & $7.7(0.8,17.2)$ \\
IRP & 44 & $16.3 \pm 7.4$ & 8 & $9.5 \pm 4.8$ \\
& & $15.0(12.0,19.8)$ & & $8.0(6.3,11.0)$ \\
\hline
\end{tabular}

$B M I$ body mass index, GERD gastroesophageal reflux disease, IRP integrated relaxation pressure, LES lower esophageal sphincter, POEM peroral endoscopic myotomy, $S D$ standard deviation
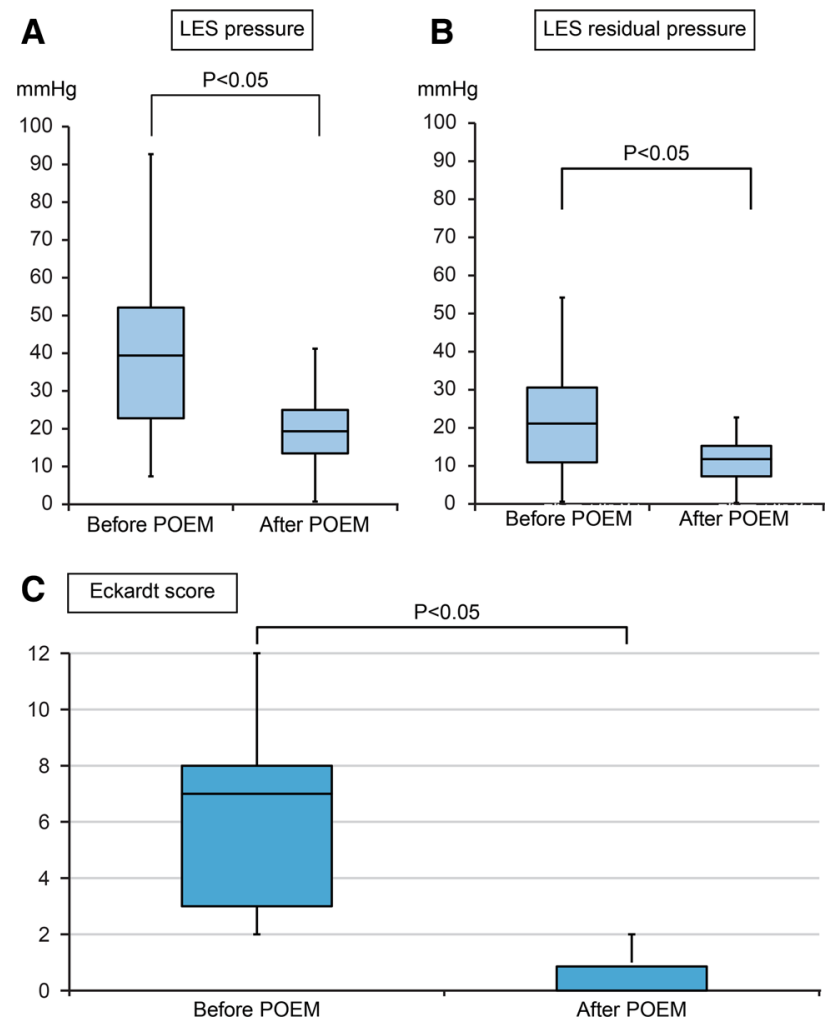

Fig. 2 A-C The mean preoperative and postoperative LES pressures are $40.0 \pm 22.8$ and $20.7 \pm 14.0 \mathrm{mmHg}$, respectively, indicating a statistically significant decrease after POEM. The mean preoperative and postoperative LES residual pressures are $22.1 \pm 13.3$ and $11.4 \pm 6.6 \mathrm{mmHg}$. The Eckardt score significantly decreased from $5.7 \pm 2.5$ preoperatively to $0.7 \pm 0.8$ postoperatively

However, POEM is known to have a curative effect, similar to the Heller myotomy. Additional fundoplication is not performed in POEM. Therefore, when POEM was first introduced, the development of GERD was also a concern. However, 6 years since the initial application of POEM, there have been no reports of the occurrence of GERD requiring surgical intervention with fundoplication.

Treatment of GERD focuses on controlling its symptoms and preventing the complications of reflux esophagitis. According to the frequency of reflux esophagitis in the

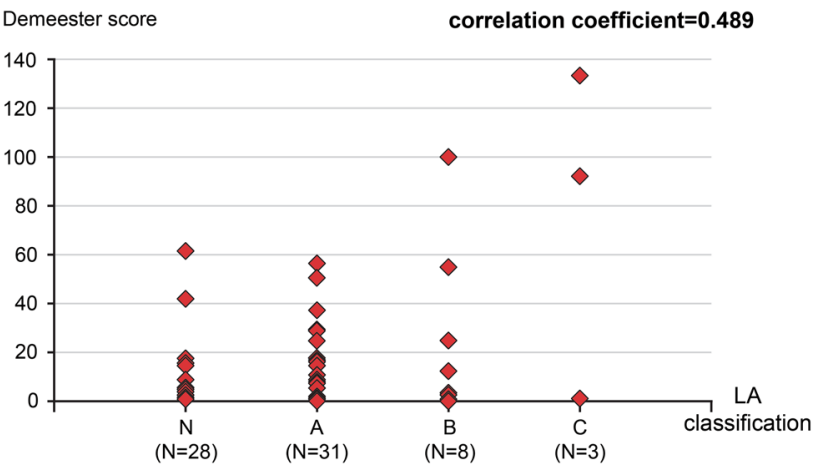

Fig. 3 Relationship between endoscopic findings of reflux esophagitis and result of 24-h $\mathrm{pH}$ monitoring. The correlation between the results of $24-\mathrm{h} \mathrm{pH}$ monitoring and endoscopy is nearly positive (correlation coefficient $=0.489$ )

postoperative endoscopic observations undertaken in this study, $84 \%$ of the patients were classified as grade $\mathrm{N}$ or A, with $12 \%$ in grade $\mathrm{B}$, and $4 \%$ in grade $\mathrm{C}$; not only endoscopy, but also 24-h pH monitoring were performed to evaluate GER and there was a positive correlation between the observations from endoscopy and $\mathrm{pH}$ monitoring (correlation coefficient $=0.489$ ). The total percent of time $\mathrm{pH}$ that was $<4$ was $13 \%(9 / 70)$. These results indicate a slightly higher incidence of postoperative GER than that observed after Heller myotomy with fundoplication and a lower incidence than that after Heller myotomy without fundoplication [7].

Furthermore, both reflux esophagitis and symptomatic GERD were well controlled with PPIs for 3 months, clinically.

Despite the same myotomy as the Heller myotomy, why is it that GERD after POEM does not become a problem clinically? Preservation of the phrenoesophageal ligament is believed to hold the key to the development of postoperative GERD. Simić et al. [34] reported that preservation of the phrenoesophageal ligament during Heller myotomy can suppress the development of GERD, regardless of whether fundoplication is performed.

Antireflux mechanisms involve the inner circular muscles, oblique muscle, crus of diaphragm, and the phrenoesophageal ligament [35]. The role of the 
Table 3 Result of logistic regression analysis for erosive gastritis Los Angeles classification: grade $\mathrm{B} / \mathrm{C}$

\begin{tabular}{|c|c|c|c|}
\hline & \multicolumn{3}{|c|}{ Univariate analysis } \\
\hline & OR & $95 \% \mathrm{CI}$ & $P$ value \\
\hline \multicolumn{4}{|l|}{ Before POEM } \\
\hline Men (vs. women) & 0.777 & $0.205-2.946$ & 0.711 \\
\hline Age & 1.010 & $0.976-1.045$ & 0.570 \\
\hline BMI & 1.046 & $0.865-1.266$ & 0.640 \\
\hline \multicolumn{4}{|l|}{ Degree of dilatation } \\
\hline I & 1.000 & Ref & \\
\hline II & 1.146 & $0.313-4.196$ & 0.837 \\
\hline III & n.c. & & \\
\hline Sigmoid type (vs. straight type) & n.c. & & \\
\hline \multicolumn{4}{|l|}{ Chicago classification } \\
\hline Type I & 1.000 & Ref & \\
\hline Type II & 0.292 & $0.045-1.899$ & 0.197 \\
\hline Type III & 0.571 & $0.057-5.775$ & 0.635 \\
\hline Primary procedure (vs. no primary procedure) & 2.022 & $0.512-7.990$ & 0.315 \\
\hline \multicolumn{4}{|l|}{ Primary procedure } \\
\hline None & 1.000 & Ref & \\
\hline Balloon dilatation & 1.792 & $0.398-8.064$ & 0.447 \\
\hline Hiatal hernia (vs. no hiatal hernia) & 5.800 & $0.335-100.459$ & 0.227 \\
\hline Eckardt score & 0.996 & $0.768-1.292$ & 0.976 \\
\hline Mean LES pressure & 0.988 & $0.952-1.026$ & 0.534 \\
\hline LES residual pressure & 0.978 & $0.920-1.040$ & 0.478 \\
\hline IRP & 0.989 & $0.942-1.039$ & 0.663 \\
\hline \multicolumn{4}{|l|}{ POEM } \\
\hline Length of procedure & 1.000 & $0.986-1.014$ & 0.974 \\
\hline Length of myotomy: total & 1.079 & $0.928-1.254$ & 0.323 \\
\hline Length of myotomy: esophageal & 1.092 & $0.930-1.282$ & 0.283 \\
\hline Length of myotomy: gastric & 0.987 & $0.530-1.839$ & 0.968 \\
\hline Postoperative stay, days & 1.102 & $0.889-1.366$ & 0.374 \\
\hline Mucosal injury & n.c. & & \\
\hline \multicolumn{4}{|l|}{3 months after POEM } \\
\hline BMI & 1.017 & $0.834-1.240$ & 0.869 \\
\hline Eckardt score & 1.071 & $0.504-2.275$ & 0.858 \\
\hline Mean LES pressure & 0.998 & $0.947-1.052$ & 0.938 \\
\hline LES residual pressure & 0.918 & $0.812-1.039$ & 0.175 \\
\hline IRP & 0.808 & $0.673-0.969$ & 0.021 \\
\hline
\end{tabular}

BMI body mass index, GERD gastroesophageal reflux disease, IRP integrated relaxation pressure, $L E S$ lower esophageal sphincter, $P O E M$ peroral endoscopic myotomy, $S D$ standard deviation, n.c. not calculated phrenoesophageal ligament is to maintain them in the appropriate location anatomically. Therefore, myotomy with complete dissection of the phrenoesophageal ligament causes anatomic slippage and, as a result, postoperative GER is likely to occur.

In contrast, myotomy preserving the phrenoesophageal ligament obtains better reflux control. This theory is the same in POEM. POEM involves division of the inner circular muscles from the esophageal lumen, and the range of the procedure remains restricted to within the longitudinal muscles. Thus, POEM preserves the adjacent structures surrounding the distal esophagus, and the phrenoesophageal ligament remains intact.

In other words, in terms of preserving the antireflux mechanism, POEM is equally or more effective than Heller myotomy in that it preserves the phrenoesophageal ligament partially. Therefore, it is natural that the rate of GERD after POEM is low.

In addition, the fact that the angle of His was preserved in all cases in this study (POEM on anterior myotomy) is 
considered to be a contributory factor that helped maintain the function of the system, thus preventing GER. In this regard, further investigations of the differences in GERD between subtypes of POEM-anterior myotomy without incision of the angle of His and posterior myotomy with incision of the angle of His-are needed.

The present study investigated whether POEM (especially myotomy of the gastric side) is associated with reflux esophagitis of grade B or higher severity. While examining the predictors of $\geq$ grade $B$ reflux esophagitis, we found that postoperative IRP significantly affected the development of $\geq$ grade $B$ reflux esophagitis. However, POEMrelated variables, such as the length of the myotomy, did not show a significant correlation with postoperative reflux esophagitis of grade B or higher severity.

As described in the beginning, decreasing the pressure at the LES is the only valid therapeutic approach to eliminate or reduce these symptoms. However, there are no precise landmarks of the LES anatomically. Thus, an extended gastric myotomy $(3 \mathrm{~cm})$ is recommended to improve the results of therapy in conventional surgery [36]. In POEM, the LES is not detected precisely during surgery. Therefore, a gastric myotomy of sufficient length is needed to improve the results of this procedure. However, for example, if the length of gastric myotomy is related to the severity of esophagitis after POEM, the length of the myotomy should be kept minimal. In this study, the myotomy itself during POEM was not associated with the severity of postoperative reflux esophagitis of grade B or higher severity, statistically.

Considering these results, an extended gastric myotomy (approximately 2-3 cm) is also recommended in POEM. In the event moderate esophagitis occurs after POEM, it can be controlled by PPIs. However, caution should be exercised during the anterior myotomy on the gastric aspect as the branch of the left gastric artery exists on the gastric side. In this study, we found POEM to be safe and effective in providing symptomatic relief for patients with achalasia. No clinically problematic development of refractory GERD occurred; furthermore, the myotomy itself during POEM was not associated with the severity of reflux esophagitis. This study has certain limitations: POEM was conducted at a single center, the number of patients was limited, and long-term outcomes were not evaluated. Thus, additional multicenter studies with larger samples and long-term outcomes are warranted.

In conclusion, POEM is safe and effective in providing symptomatic relief for patients with achalasia. No clinically significant development of refractory GERD occurred; furthermore, the myotomy itself during POEM was not associated with reflux esophagitis of grade B or higher severity. Therefore, an extended gastric myotomy is recommended in the POEM procedure to improve the results of therapy as well as conventional surgery.
Acknowledgments The authors thank Hajime Yamakage (Satista) for his helpful advice regarding the statistical methods followed and all clinical staff for their contribution to this study.

\section{Compliance with ethical standards}

Disclosures Drs. Hironari Shiwaku, Haruhiro Inoue, Takamitsu Sasaki, Kanefumi Yamashita, Toshihiro Ohmiya, Shinsuke Takeno, Satoshi Nimura, and Yuichi Yamashita have no conflicts of interest associated with this work.

\section{References}

1. Richter JE (2001) Oesophageal motility disorders. Lancet 358:823-828

2. Gelfand MD, Kozarek RA (1989) An experience with polyethylene balloons for pneumatic dilation in achalasia. Am J Gastroenterol 84:924-927

3. Boeckxstaens GE, Annese V, des Varannes SB et al (2011) Pneumatic dilation versus laparoscopic Heller's myotomy for idiopathic achalasia. N Engl J Med 364:1807-1816

4. Tanaka Y, Iwakiri K, Kawami N et al (2010) Predictors of a better outcome of pneumatic dilatation in patients with primary achalasia. J Gastroenterol 45:153-158

5. Pasricha PJ, Ravich WJ, Kalloo AN (1993) Botulinum toxin for achalasia. Lancet 341:244-245

6. Swanstrom LL, Pennings J (1995) Laparoscopic esophagomyotomy for achalasia. Surg Endosc 9:286-290 (discussion 90-2)

7. Campos GM, Vittinghoff E, Rabl C et al (2009) Endoscopic and surgical treatments for achalasia: a systematic review and metaanalysis. Ann Surg 249:45-57

8. Rebecchi F, Giaccone C, Farinella E, Campaci R, Morino M (2008) Randomized controlled trial of laparoscopic Heller myotomy plus Dor fundoplication versus Nissen fundoplication for achalasia: long-term results. Ann Surg 248:1023-1030

9. Richards WO, Torquati A, Holzman MD et al (2004) Heller myotomy versus Heller myotomy with Dor fundoplication for achalasia: a prospective randomized double-blind clinical trial. Ann Surg 240:405-412 (discussion 12-5)

10. Bonavina L, Nosadini A, Bardini R, Baessato M, Peracchia A (1992) Primary treatment of esophageal achalasia. Long-term results of myotomy and Dor fundoplication. Arch Surg 127:222-226 discussion 7

11. Stewart KC, Finley RJ, Clifton JC, Graham AJ, Storseth C, Inculet R (1999) Thoracoscopic versus laparoscopic modified Heller Myotomy for achalasia: efficacy and safety in 87 patients. J Am Coll Surg 189:164-169 (discussion 9-70)

12. Robert M, Poncet G, Mion F, Boulez J (2008) Results of laparoscopic Heller myotomy without anti-reflux procedure in achalasia. Monocentric prospective study of 106 cases. Surg Endosc 22:866-874

13. Maher JW, Conklin J, Heitshusen DS (2001) Thoracoscopic esophagomyotomy for achalasia: preoperative patterns of acid reflux and long-term follow-up. Surgery 130:570-576 (discussion 6-7)

14. Bloomston M, Boyce W, Mamel J et al (2000) Videoscopic Heller myotomy for achalasia-results beyond short-term followup. J Surg Res 92:150-156

15. Shiino Y, Filipi CJ, Awad ZT, Tomonaga T, Marsh RE (1999) Surgery for achalasia: 1998. J Gastrointest Surg 3:447-455

16. Ferguson MK (1991) Achalasia: current evaluation and therapy. Ann Thorac Surg 52:336-342

17. Costantini M, Zaninotto G, Guirroli E et al (2005) The laparoscopic Heller-Dor operation remains an effective treatment for 
esophageal achalasia at a minimum 6-year follow-up. Surg Endosc 19:345-351

18. Heller E (1914) Extramukose Kardioplastik beim chronischen Kardiospasmus mit Dilatation des Oesophagus. Mitteilungen aus den Grenzgebieten der Medizin und Chirurgie 27:141

19. Inoue H, Minami H, Kobayashi $Y$ et al (2010) Peroral endoscopic myotomy (POEM) for esophageal achalasia. Endoscopy $42: 265-271$

20. Swanstrom LL, Kurian A, Dunst CM, Sharata A, Bhayani N, Rieder E (2012) Long-term outcomes of an endoscopic myotomy for achalasia: the POEM procedure. Ann Surg 256:659-667

21. von Renteln D, Inoue H, Minami H et al (2011) Peroral endoscopic myotomy for the treatment of achalasia: a prospective single center study. Am J Gastroenterol 107:411-417

22. Minami H, Isomoto $H$, Yamaguchi $N$ et al (2014) Peroral endoscopic myotomy for esophageal achalasia: clinical impact of 28 cases. Dig Endosc 26:43-51

23. Familiari P, Gigante G, Marchese M et al (2014) Peroral endoscopic myotomy for esophageal achalasia: outcomes of the first 100 patients with short-term follow-up. Ann Surg. doi:10.1097/ SLA.0000000000000992

24. Eckardt VF, Aignherr C, Bernhard G (1992) Predictors of outcome in patients with achalasia treated by pneumatic dilation. Gastroenterology 103:1732-1738

25. Armstrong D, Bennett JR, Blum AL et al (1996) The endoscopic assessment of esophagitis: a progress report on observer agreement. Gastroenterology 111:85-92

26. Johnson LF, Demeester TR (1974) Twenty-four-hour pH monitoring of the distal esophagus. A quantitative measure of gastroesophageal reflux. Am J Gastroenterol 62:325-332

27. Johnson LF, DeMeester TR (1986) Development of the 24-h intraesophageal $\mathrm{pH}$ monitoring composite scoring system. J Clin Gastroenterol 8(Suppl 1):52-58
28. Demeester TR, Johnson LF, Joseph GJ, Toscano MS, Hall AW, Skinner DB (1976) Patterns of gastroesophageal reflux in health and disease. Ann Surg 184:459-470

29. Dindo D, Demartines N, Clavien PA (2004) Classification of surgical complications: a new proposal with evaluation in a cohort of 6336 patients and results of a survey. Ann Surg 240:205-213

30. Stavropoulos SN, Modayil RJ, Friedel D, Savides T (2013) The International Per Oral Endoscopic Myotomy Survey (IPOEMS): a snapshot of the global POEM experience. Surg Endosc 27:3322-3338

31. Stavropoulos SN, Desilets DJ, Fuchs KH et al (2014) Per-oral endoscopic myotomy white paper summary. Gastrointest Endosc 80:1-15

32. Shiwaku H, Inoue H, Beppu R et al (2013) Successful treatment of diffuse esophageal spasm by peroral endoscopic myotomy. Gastrointest Endosc 77:149-150

33. Khashab MA, Messallam AA, Onimaru M et al (2015) International multicenter experience with peroral endoscopic myotomy for the treatment of spastic esophageal disorders refractory to medical therapy (with video). Gastrointest Endosc 81:1170-1177

34. Simic AP, Radovanovic NS, Skrobic OM, Raznatovic ZJ, Pesko PM (2010) Significance of limited hiatal dissection in surgery for achalasia. J Gastrointest Surg 14:587-593

35. Mittal RK, Balaban DH (1997) The esophagogastric junction. N Engl J Med 336:924-932

36. Oelschlager BK, Chang L, Pellegrini CA (2003) Improved outcome after extended gastric myotomy for achalasia. Arch Surg 138:490-495 (discussion 5-7) 